\title{
FISS - A Factor-based Index of Systemic Stress in the Financial System ${ }^{1}$
}

\author{
Tibor Szendrei, Central Bank of Hungary; Heriot-Watt University \\ ts136@hw.ac.uk \\ Katalin Varga, Central Bank of Hungary \\ vargaka@mnb.hu
}

Tracking and monitoring stress within the financial system is a key component of macroprudential policy. This paper introduces a new measure of contemporaneous stress: the Factor-based Index of Systemic Stress (FISS). The aim of the index is to capture the common components of data describing the financial system. This new index is calculated with a dynamic Bayesian factor model methodology, which compresses the available high frequency and high dimensional dataset into stochastic trends. Aggregating the extracted four factors into a single index is possible in a multitude of ways, but averaging yields satisfactory results. The contribution of this paper is the usage of the dynamic Bayesian framework to measure financial stress, as well as producing the measure in a timely manner without the need for deep option markets. Applied to Hungarian data the FISS is a key element of the macroprudential toolkit.

Keywords: systemic stress, financial stress index, Dynamic Bayesian Factor Model, financial system, macroprudential toolkit

JEL Codes: G01, G10, G20, E44
Citation: Szendrei, T. and Varga, K. (2020). FISS - A Factor-based Index of Systemic Stress in the Financial System. Russian Journal of Money and Finance, 79(1), pp. 3-34.

doi: $10.31477 /$ rjmf.202001.03

\section{Introduction}

Tracking and monitoring financial stress is a key component of financial stability. There are many policy instruments (e.g. release of countercyclical capital buffers) that rely on knowledge of the level of financial stress in the financial system. Using these policy instruments when the stress is not adequately high carries the cost of an inability to implement the same policy in the near future if

\footnotetext{
1 The opinions expressed in this paper are those of the authors and do not necessarily represent the official views of the Central Bank of Hungary. The paper has benefited from the helpful insights of Péter Elek, Zsuzsanna Hosszú, Gergely Lakos, Miklós Sallay and Jan Klacso, as well as the guidance of László Márkus. Any omissions are the responsibility of the authors.
} 
the need arises. The aim of the Factor-based Index of Systemic Stress (hereinafter FISS) is to capture the current level of systemic stress prevalent in the Hungarian financial system.

The literature in recent years has introduced several econometric methods for developing financial stress indices (hereinafter FSI) and financial conditions indices (hereinafter FCI). Both types of indices compress a wide range of financial variables into a single series, but FCIs and FSIs are inversely related during financial instability: increasing financial stress means worsening financial conditions. An FSI narrowly focuses on measuring financial stress (e.g. Hakkio and Keeton, 2009), while an FCI focuses on broad measures of financial conditions (e.g. Koop and Korobilis, 2014). Due to this wider range, FCIs frequently include macroeconomic variables as well as financial variables. The FISS falls in the category of an FSI, as its aim is to measure the level of financial stress.

There are multiple ways to estimate an FSI which range from simple weighted averaging to more complex econometric methods. This diversity in methodologies is driven by the need to include more financial variables which has been steadily increasing in the past decade. Coupled with advances in computing power, more complex econometric models have become commonplace in the literature. In this paper the FISS uses a dynamic Bayesian factor model framework to compress information from 19 financial variables into four factors. The choice of four factors was supported on both intuitive grounds (data from four financial markets was used), and empirical grounds (four factors yielded an explanatory power of around $85 \%$ ). Furthermore, the factors were allowed to follow non-stationary paths. As such, the factors are the common stochastic trends of the data. This was done because differencing the daily data would lead to a potential loss of information.

To aggregate the four factors, the usual weighing scheme used in principal component analysis could not be applied, as the factors are non-orthogonal after the imposition of a dynamic structure on them. On account of this, several methodologies were tested: simple average, quantile regression (hereinafter $\mathrm{QR}$ ), information value (hereinafter IV), and a simulation procedure. The final results did not yield significant differences from the simple average and as such it was used for aggregation.

This paper contributes to the literature in two aspects. First, it creates a nonstationary factor model to capture financial instabilities. Such an approach has not been taken in the literature of FSI to the knowledge of the authors. Further, the paper uses Hungarian data, signifying that the methodology of the FISS can be used for emerging economies. This later contribution is particularly important because it highlights that accurate FSIs can be constructed in the absence of data from deep option markets, which emerging markets lack.

Section 2 of the paper discusses the concept of financial stress and systemic stress, and gives a brief literature review of other FSIs available. The aim of this Section is to give an economic intuition of what a FSI aims to capture. Section 3 gives an overview 
of the variables selected in the model, categorised by the financial market the variable aims to capture. This Section also discusses how the data were transformed, and the motivation for each transformation. Section 4 discusses the dynamic Bayesian factor model framework and briefly discusses the aggregation methods considered. Section 5 shows the results of the FISS. Finally, Section 6 concludes.

\section{Financial stress}

Financial stress can be interpreted as the amount of risk which has materialised. This definition implies that financial stress can be measured by a continuous variable with its extreme values representing crisis events. The most common indication of these events is an acute shift in investors' intention to hold less risky assets, called flight to quality, and liquid assets, called flight to liquidity (Caballero and Krishnamurthy, 2008; Hakkio and Keeton, 2009). This shift in intention is primarily driven by increased uncertainty in the market, increased information asymmetry between market participants and changing risk preferences. It is important that an FSI not only includes variables that capture flight to quality and flight to liquidity, but also indicators that measure increased uncertainty and information asymmetry, to better measure the continuous range of financial stress.

Increased uncertainty in the financial market can stem from two sources: asset valuation and the behaviour of other market participants. Asset valuation involves a lot of ambiguity and some unexpected development - often referred to as a Minsky moment ${ }^{2}$ - can trigger market participants to re-evaluate their previous estimates. This in turn increases the disagreement about the underlying assets' value, because the actors' asset valuation differs. This is embodied by increasing volatility in the market.

Perhaps the more pertinent source of uncertainty after a Minsky moment is the behaviour of other market participants. The price of an asset is not influenced only by the underlying dividend stream, but also by the selling pressure of other actors. Increased uncertainty about the behaviour of others might induce a trader to liquidate her position early. Fire sales can develop when such a decision is taken by multiple actors in the face of increased uncertainty.

Information asymmetry in the financial markets occurs when one party has more information about a product than the other. There are a variety of cases when information asymmetry can occur in financial markets (e.g. borrowers have more information than lenders, sellers on secondary markets have more information about the asset than buyers, participants in a swap deal have more information about themselves than about the respective counterparty, etc.). Information gaps can worsen during financial stress due to market participants becoming doubtful

\footnotetext{
2 'Minsky moment' is a name derived from Minsky's financial instability hypothesis (see Kindleberger and Aliber, 2011).
} 
about the accuracy of their information about the other parties. This is further exacerbated by the fact that during periods of high financial stress the value of potential collaterals, which aims to tackle information asymmetry on financial markets, is expected to decline (Gorton, 2009). This manifests itself in a higher cost of borrowing and lower lending activity. The decline of lending activity is further worsened by firms not knowing for certain their banks' solvency situation and, on account of this, not knowing if they can count on their credit lines. On secondary markets the increased information gap lowers the average price of the asset.

Risk preferences are non-constant in time. It is well documented that market participants tend to underestimate risks during bull markets and overestimate risks during episodes of high financial stress (Kindleberger and Aliber, 2011; Freixas et al., 2015). This changing risk preference further reduces market activity for riskier assets during stressful periods.

Shifting exposures to more liquid and less risky assets is rational at an individual level, as it can limit the risk of potential losses that could arise due to the aforementioned effects. On account of the flight to quality, the spread between risky and less risky assets widens as market participants flock to safe assets (Caballero and Kurlat, 2008).

Flight to liquidity is a result of market participants' fear of not being able to sell illiquid assets close to their fundamental value when the market participants need cash quickly. ${ }^{3}$ The effect of flight to liquidity is an increase in the liquidity risk premia demanded for illiquid assets and a widening of the spread between liquid and less liquid assets' returns.

Systemic stress is a subcategory of financial stress and can be defined as the situation where financial stress becomes so widespread that it impairs several financial institutions and markets in an economy (De Bandt and Hartmann, 2000). This contagion-like spread of financial stress is not limited to the borders of a country. Due to tight cross-border financial interlinkages, financial stress in the market of one country can spread across a region. Accounting for these elements is important when trying to measure the financial stress of a small, open economy.

Systemic stress on the financial markets can be damaging to the real economy as well, because it impedes financial intermediation. During periods of high systemic stress, financial market participants have limited possibilities to hedge on the market, which may force them to limit their activity to only the most liquid and least risky markets. This raises the cost of doing business for all firms on the market and the net effect is a decrease in investment. As such, quantifying and monitoring systemic stress is of key importance.

The financial markets of each economy are different in their level of development and depth. As a result of this, there exist several financial stress

\footnotetext{
${ }^{3}$ For more information about the aspects of liquidity that differentiate markets, see Páles and Varga (2008).
} 
indices in the literature. What follows is a non-exhaustive survey of some of the FSIs that have been created so far.

Illing and Liu (2006) make an influential contribution to the literature on financial indices. The authors test several aggregation methods to create a daily FSI that best represents the Canadian financial markets. The authors identify episodes of high financial stress based on a survey they conducted among Bank of Canada policy makers. Their best performing FSI uses 11 financial variables and is aggregated using a weighted average methodology where the weights are determined by the relative size of the financial market the indicator in question is associated with.

Nelson and Perli (2007) create a weekly FSI for the US economy using 12 variables. The authors employ a two-step approach to create their desired measure of financial stress. In the first step, they create three summary indicators: level factor, rate of change factor and correlation factor. The level factor is constructed by calculating the weighted average of the variance-normalised indicators. The rate of change factor is the rolling 8-week percentage change in the level factor. The correlation factor is the first principal component of the 11 variables on a rolling 26-week window. The three constructed factors are aggregated into one index with the help of a probit regression on a pre-defined binary crisis indicator.

Hakkio and Keeton (2009) build their indicator using 11 daily financial market variables. They do so in one step using principal component analysis on the standardised variables. The idea is that financial stress is the factor responsible for most of the variance observed in the series. Hatzius et al. (2010) use the idea of factor analysis as well and apply it to 45 distinct data series in an effort to create an FCI. The authors test how their FCI fares in forecasting GDP. The conclusion of the paper is that, while multiple factors are necessary to capture the co-movement of the financial variables, only the first factor is helpful in forecasting real activity. These results are crucial, as they highlight how modelling financial systems might only be possible with the help of multiple factors.

The next two indicators presented here are the Composite Index of Systemic Stress (CISS) created by Holló et al. (2012) and the System Wide Financial Stress Indicator (SWFSI) developed by Holló (2012). The CISS and SWFSI use the same methodology, with the only difference being that the CISS was constructed for the euro area and the SWFSI was made to capture the stress levels of the Hungarian economy. This methodology requires the chosen variables to be transformed using sample CDF, so that all the variables are on the same $(0,1]$ ordinal scale. These variables are then categorised into the financial markets they represent. The sub-indices are the arithmetic average of these categorised transformed variables. To create a single index out of the sub-indices, the CISS and SWFSI use portfolio theory to give more weight to stress events where the indices are correlated. This correlation matrix is time varying. Furthermore, the sub-indices also receive an additional weight according to how much the 
sub-index influences the real economy, measured by industrial production (hereinafter IP). ${ }^{4}$

As mentioned, the CISS is constructed for the EU market and the SWFSI was developed with the Hungarian economy in mind. This difference influences the selection of variables and the number of sub-indices created. The CISS aggregates 15 variables into five sub-indices, while the SWFSI uses 27 indicators to create six sub-indices.

Apart from the SWFSI, there have been other attempts at creating an FSI for emerging markets. One such paper is Cevik et al. (2013), where the authors construct an index for Bulgaria, the Czech Republic, Hungary, Poland, and Russia. In creating the FSIs, the paper uses six core components to gauge financial stress: banking sector fragility, security market risk, currency risk, external debt, sovereign risk and trade finance. These six variables are aggregated using principal component analysis and the first factors are used as the FSIs of each country.

One important conclusion of the literature review is that there exists no consensus in how to create an FSI: the indices currently available differ in their methodology as well as their variable selection. It is therefore important to have a rigorous data selection procedure that is guided by economic considerations. This also implies that, on account of different market structures across different countries, the selection of indicators will vary. Furthermore, financial markets are elusive and ever-changing, necessitating frequent and varying attempts at measuring financial stress.

\section{Data selection and transformation}

The aim of the FISS is to capture financial stress in the financial system of Hungary. Thus, following SWFSI and CISS, different segments of the financial system were defined for data collection. Four segments were identified: the government bond market, the foreign exchange market, the bank segment and interbank market, and the capital market. To get a good mix of financial data that is not influenced excessively by market deepening, the starting point was set at 1 January 2005.

The selection of potential variables was constrained by further data requirements. First of all, the aim of the FISS is to quantify financial stress in a timely manner, thus only daily data were considered. Second, movements in the indicator should capture developments that are market wide. Finally, the variables in the model should capture some feature of financial stress outlined in Section 2. Additionally, as the Hungarian financial markets are open and closely connected to their European counterparts, variables that capture increased uncertainty in the European markets were considered as indicators of potential cross border contagion effects.

\footnotetext{
${ }^{4}$ This is calculated with the help of Impulse Response functions in a vector autoregression (VAR). These weights can be time varying as well to account for structural changes in the economy if necessary.
} 
Table 1. List of variables included in the FISS

\begin{tabular}{|c|c|c|}
\hline & Raw variable & Aspect of financial stress captured \\
\hline \multirow{3}{*}{$\begin{array}{l}\text { Government } \\
\text { bond market }\end{array}$} & Risk premium on 5-year bond & Flight to quality \\
\hline & Yield on 3-month bond & \multirow[t]{2}{*}{ Increased uncertainty } \\
\hline & Yield on 10-year bond & \\
\hline \multirow{5}{*}{$\begin{array}{l}\text { Foreign exchange } \\
\text { market }\end{array}$} & EUR/HUF volatility $(\alpha=0.95)$ & \multirow[t]{4}{*}{ Increased uncertainty } \\
\hline & USD/HUF volatility ( $\alpha=0.95)$ & \\
\hline & CHF/HUF volatility $(\alpha=0.95)$ & \\
\hline & GBP/HUF volatility $(\alpha=0.95)$ & \\
\hline & Bid-Ask spread (EUR) & Flight to liquidity \\
\hline \multirow[t]{5}{*}{ Capital market } & CMAX of BUX (60 day window) & \multirow{2}{*}{$\begin{array}{l}\text { Increased uncertainty, } \\
\text { flight to quality }\end{array}$} \\
\hline & CMAX of BUMIX ( 60 day window) & \\
\hline & CMAX of CETOP20 (60 day window) & Increased uncertainty, contagion \\
\hline & CMAX of DAX (60 day window) & Increased uncertainty, contagion \\
\hline & VDAX & Increased uncertainty, contagion \\
\hline \multirow[t]{6}{*}{$\begin{array}{l}\text { Bank segment } \\
\text { and interbank market }\end{array}$} & Harmonic Distance & $\begin{array}{l}\text { Increased information asymmetry, } \\
\text { liquidity drought }\end{array}$ \\
\hline & Domestic Banks PD & Increased uncertainty \\
\hline & Foreign Banks PD & Increased uncertainty, contagion \\
\hline & 3-month BUBOR & \multirow{2}{*}{$\begin{array}{l}\text { Increased uncertainty, } \\
\text { increased information asymmetry, } \\
\text { flight to liquidity }\end{array}$} \\
\hline & Overnight rate of HUFONIA & \\
\hline & Turnover of HUFONIA & $\begin{array}{l}\text { Increased information asymmetry, } \\
\text { liquidity drought }\end{array}$ \\
\hline
\end{tabular}

Out of the considered variables, 19 were chosen that maximise the explained variance. In doing so, all possible combinations of the variables were tested to see which selection yields the best explanatory power while not including variables that offer limited information. Although factor analysis is capable of handling the inclusion of all the variables, Boivin and $\mathrm{Ng}$ (2006) found that including fewer, but pre-screened, variables in the factor model yielded results as good as, if not better than, using all the available series. The final list of variables is shown in Table 1. The following Sections detail the final variable selection. For the full list of variables considered see Appendix 1.

\subsection{Government bond market}

The government bond market is captured by three variables: risk premium on the 5-year government bond compared to the German 5-year government bond, reference yield on the 3-month bond and the reference yield on the 10-year bond.

The risk premium measure is chosen as it can capture episodes of flight to quality. As such, it yields information about traders' expectations about the Hungarian economy compared to Germany. For the calculation of this risk premium, the German government bond was chosen as it is the closest substitute to a euro area bond. The choice of Germany as a base is further supported by the 
fact that the Hungarian economy is intertwined with the German economy. Thus, using German bond yields as a base gives a better measure of the idiosyncratic stress of the Hungarian government bond market.

The yields on the 3-month government bond and the 10 -year government bond together represent the yield curve. In effect, during elevated levels of financial stress, the short-term outlook of an economy becomes uncertain, raising the short-term yield. This can lead to an inversion of the yield curve, a situation where short-term bond yields exceed long-term yields, which captures the increased uncertainty in the market.

These two price-based measures capture forward-looking aspects of financial stress. This is useful for an FSI, as it can measure how materialised risk influences actors' expectations about future risks. The FSI will still be a measure of materialised risks, but, with the inclusion of forward-looking measures, the full effect can be captured, as stress is derived not only from past events, but also from market participants' uncertainty about future outcomes.

\subsection{Foreign exchange market}

Five variables encapsulate the foreign exchange market in the model: EUR/HUF spot market volatility, USD/HUF spot market volatility, CHF/HUF spot market volatility, GBP/HUF spot market volatility, and the bid-ask spread of EUR offers on the spot market.

The volatility measures together aim to capture uncertainty surrounding the Hungarian forint. Multiple currency pairs were included so as to make sure that only volatility related to the Hungarian markets is captured. Out of all the currencies, the volatility of the Hungarian forint with respect to the euro is of key importance due to the economic links between the Hungarian economy and the euro zone.

To calculate the volatility of the currency, an exponentially weighted standard deviation (hereinafter EWSD) of the daily log change with a delay parameter of 0.95 was chosen. Standard deviation on daily log changes of currencies is commonly used to measure exchange rate volatility (see Hooper and Kohlhagen, 1978; Akhtar and Hilton, 1984; Gotur, 1985) due to its simplicity in calculation and the fact that it requires no assumptions to be made to fit the model. Because the aim of the FISS is to capture financial stress in a timely manner, exponential weighting was imposed on the standard deviation so that older observations have a lower impact on the current level of standard deviation. The EWSD was calculated with the following formula:

$$
\sqrt{\frac{\sum_{i=1}^{N} w_{i}\left(x_{i}-\bar{x}^{*}\right)^{2}}{\sum_{i=1}^{N} w_{i}-\frac{\sum_{i=1}^{N} w_{i}^{2}}{\sum_{i=1}^{N} w_{i}}}}
$$


where $w_{i}$ is the weight and $\bar{x}^{*}$ is the exponentially weighted moving average using the same weighting setup.

Although a generalised autoregressive conditional heteroskedasticity model (GARCH) or an approach using variance from the long-term trend might be better at identifying episodes of high exchange rate volatility, there is no guarantee that the same model will hold as newer data is added to the sample. Due to this robustness concern, the simpler EWSD approach was favoured.

In deciding on the decay factor, the following values were considered: $0.85,0.9$, and 0.95 . The EWSD of each decay factor is shown in Figure 1. Upon inspecting Figure 1, it is visible that the EWSD of the delay factors of 0.9 and 0.85 drop deeper after reaching their maximum value only to rebound instantly during the crisis. Such erratic movement is not desirable and as such the delay factor of 0.95 was chosen. Larger values than 0.95 were not considered, because in that case weights (albeit small ones) are given to observations that occurred over 90 days ago. One major drawback of using this measure of volatility is that it is backward-looking and has no information about the expectation of investors.

Figure 1. EUR/HUF exponentially weighted standard deviation with different decay factors

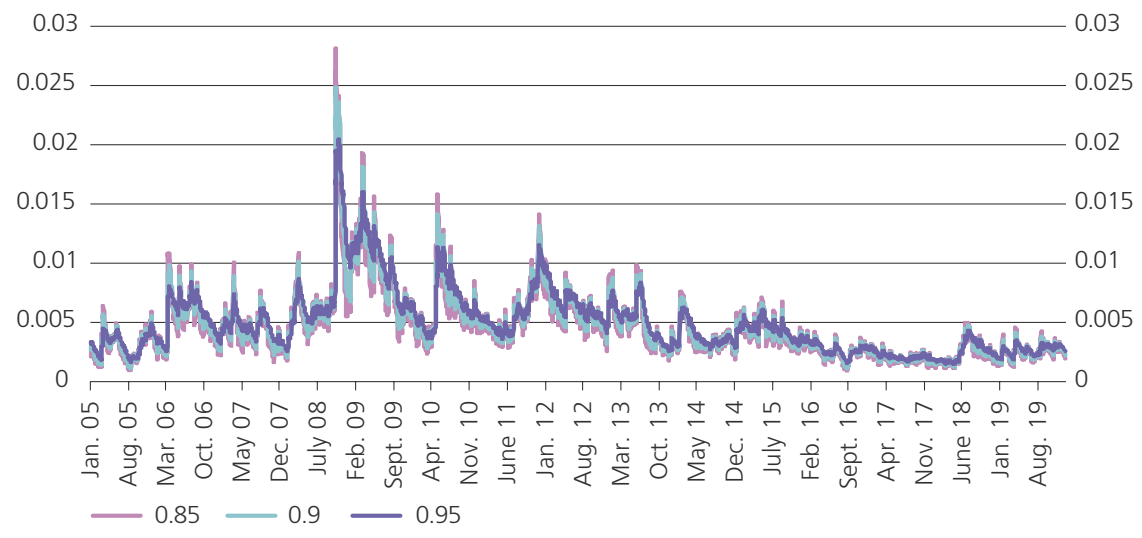

Bid-ask spreads are frequently used to measure the liquidity risk of a market (Holló, 2012; Páles and Varga, 2008). In periods of low financial stress, the bid-ask spread is low, which shows a low transaction cost associated with doing business. High bid-ask spread is associated with increased liquidity risk during periods of adverse market conditions. This is because, during high stress periods, market participants are less inclined to enter an illiquid market, or will do so only at a price below its fundamental value, leading to lower bid prices being registered. At the same time, market participants partaking in a flight to liquidity want to sell the asset as close to its fundamental value as possible to not incur needless losses. It should be noted that a spike in bid-ask spread can occur during periods of low financial stress as well, due to structural factors (e.g. due to new issuance, 
market concentration, etc.). As such, it is important to have other measures of the foreign exchange market stress level to maximise the information content of the bid-ask spread.

\subsection{Capital market}

Several stock market indices were included to capture the movement of the Hungarian capital market. These are the BUX, BUMIX, and the CETOP20. The BUX is the primary capital market index of Hungary and includes the 14 major Hungarian companies trading on the Budapest Stock Exchange (hereinafter BSE). In its aggregation method it is equivalent to the American Dow Jones Industrial Average and the German DAX. The BUMIX is a stock market index of 25 small- and medium-sized companies listed on the BSE. The calculation is the same as for the BUX, with the exception that only companies with market capitalisation less than 125 billion Forints are included. The BUMIX and the BUX together can capture flight-to-quality aspects, as it is expected that the BUMIX will react to financial stress faster than the BUX, which includes larger firms in its composition.

The CETOP20 follows the performance of the 20 companies with the biggest market capitalisation in the Central European region. There is a condition applied during the construction of the index, which is that only seven companies from one stock exchange may be included in the index. The index serves as a benchmark for the region. The index included in the variable selection to capture aspects of region-specific stress.

The CMAX methodology was imposed on these stock market indices, which is common practice in the literature (Illing and Liu, 2006; Holló et al., 2012; Holló, 2012). It uses the following formula to construct a series to capture cumulative losses on the stock market:

$$
C M A X_{t}=1-\frac{x_{t}}{\max \left[x \in\left(x_{t-j} \mid j=0,1, \ldots, T\right)\right]},
$$

where $x_{t}$ is the stock market index at time $t$ and $T$ is the moving average window.

The idea behind the CMAX is that it compares the current value of the stock market to its maximum value over the rolling window. This value is then subtracted from 1 to get an index that increases when the cumulative losses increase. The CMAX's strength is that it is a hybrid loss-volatility measure, as high values do not just mean cumulated losses, but also increased uncertainty in the market. Following the SWFSI, the size of the rolling window was chosen to be smaller (60 days) than is common in the literature, where it is ordinarily 1-2 years. This was done on account of the FISS aiming to capture financial stress, as opposed to trying to identify stock market crashes. The smaller window means that the values from the CMAX represent only the most recent market developments. 
The VDAXNEW (hereinafter VDAX) was also included as a variable to measure the stress of the capital markets. The VDAX measures the level of volatility to be expected on the DAX in the next 30 days. The calculation methodology is equivalent to that of the VIX index, which measures the implied volatility of the S\&P 500. The strength of the VDAX is that it is a completely forward-looking index and can capture market participants' expectations about the near future. The inclusion of the VDAX and CMAX of the DAX in the model is motivated by the desire to capture contagion effects. As mentioned previously, the two economies are intertwined, and difficulties in the German capital markets can influence companies with Hungarian subsidiaries, which in turn can have a knock-on effect on the Hungarian capital markets.

\subsection{Bank segment and interbank market}

The bank segment is the largest market in the model, composed of six variables: harmonic distance measure of bank network, Domestic Banks' Probability of Default (hereinafter PD), Foreign Banks' PD, the average daily rate on 3-month unsecured interbank loans as indicated on the BUBOR, the average daily overnight rate on unsecured interbank loans as measured by the Hungarian Forint Overnight Index Average (hereinafter HUFONIA), and total turnover per day of the HUFONIA. This was done intentionally: to get an accurate representation of the stress level of the Hungarian financial market, an accurate measure of bank segment and interbank stress is necessary on account of the financing of the Hungarian economy being bank based.

The aim of using a network measure was to capture tensions present in the banking system as a whole. Such measures indicate when banks' lending behaviour reverses on the interbank market: banks stop lending to each other and instead focus on paying back their loans. This is a clear indication of increased information asymmetry. Four measures of this type were tested: harmonic distance, betweenness, closeness, and the sum of the degrees. Fukker (2017) shows that, for the Hungarian banking system, betweenness performs worse than the other three measures using a factor model as a way to evaluate the different measures. We follow Fukker (2017) in choosing harmonic distance out of the aforementioned variables, as this measure increases the variance while exercising an effect on more factors. The idea of including a network variable in an FSI is not novel and has been suggested in Hałaj and Kok (2013).

It has to be noted that the network measures perform well partly due to their close link to global turnover. On account of this, network indicators are also good indicators of liquidity droughts, which occur when market liquidity abruptly decreases during episodes of high financial stress.

HUFONIA turnover was also included alongside the harmonic distance variable to give an explicit measure of decreases in market liquidity. The HUFONIA 
is an unsecured market and elevated financial stress can be captured well on this market. This variable is also a measure of information asymmetry but measures the overall lending activity of the interbank market, instead of measuring the shifts in the behaviour of banks which harmonic distance captures.

Bank PD measures the vulnerability of a bank and the uncertainty associated with the bank in question. The banks were grouped according to whether their ownership is domestic or foreign. This was done for two reasons: for banks which are foreign subsidiaries, CDS was available for their parent banks, and foreign banks' lending activity may be influenced by the level of financial stress in the markets of their parent companies. Due to the latter, it is deemed necessary to separate foreign and domestic banks, as this way the model can capture crossborder contagion effects on the interbank market. For the domestic banks, the PD was calculated using the Merton (1974) model. ${ }^{5}$ The individual banks were weighted according to their asset size to get a single PD for domestic and foreign banks.

The final two measures in this category are the daily rates on the unsecured interbank market. These are similar to the measure of turnover in that, due to the unsecured nature, financial stress appears in these indicators early. Including both the overnight and the 3-month rates helps the model gauge market participants' expectations about the near future. Furthermore, these price variables, together with the PD indicators, carry information about the prevalence of information asymmetry in the market.

\section{Methodology}

\subsection{Dynamic factor model}

The literature on factor models in macroeconomics is extensive: Bernanke and Boivin (2003) introduce factor methods among macroeconomists, while Geweke and Zhou (1996), Otrok and Whiteman (1998) and Kose at el. (2003), among others, implement Bayesian estimation within a factor model framework. Later, Bernanke et al. (2004) and Stock and Watson (2005) enhance the factor approach with VAR methods, yielding the FAVAR.

Dynamic factor models (DFMs) were originally introduced by Geweke (1977), who extended factor models to time series data. The core idea of DFMs is that the temporal structure of the data induces persistence which must be taken into account when compressing the numerous variables. The explanatory power of DFMs is best portrayed in Sargent and Sims (1977), whose model explains a large fraction of the variance of the most important macroeconomic variables of the United States.

\footnotetext{
${ }^{5}$ More information on the Merton model is provided in Appendix 3.
} 
In the early 2000s, economists became more interested in large-dimensional DFMs. The attractiveness of these models is in their ability to handle the persistent nature of the data and to analyse large panels of time series while handling the curse of dimensionality. These types of models proved capable in forecasting and performing policy analysis by studying the impulse response functions in, e.g., a FAVAR setting (see Stock and Watson, 2002, 2005; Giannone et al., 2006, 2008; Forni et al., 2000, 2005, 2009).

Until recently, large-dimensional factor models were mainly used in stationary settings. This is at odds with the time-series literature, where the bulk of the time series describing systemic stress are I(1) (Barigozzi et al., 2020). As such, there are fundamentally two possibilities. The first option is to follow the Box-Jenkins methodology in differencing the data until stationarity is achieved and then applying standard principal component analysis (PCA) to consistently estimate the model (Stock and Watson, 2002; Bai and Ng, 2002; Bai, 2003). This method has the advantage of simplicity and statistical consistency, but has a serious drawback, as it purges any persistence in the data which might be of importance when wanting to draw conclusions about financial stress.

The second option is to fit a DFM in order to capture the autocorrelation of the time series. The core motivation for taking this route is that differencing the series purges the non-stationary common component. Statistically, this component is the common stochastic trend of the data series, namely the stress factor of interest (Bai, 2004; Barigozzi et al., 2020). Therefore, to capture the systemic stress factors, a factor model has to be fit without transforming the data to stationary. This solution was first introduced by Engle and Watson (1981) and later extended by Bai (2004) with the so-called common stochastic trend approach. In this case, the model can be consistently estimated with maximum likelihood by applying the Expectation Maximisation algorithm. The FISS builds upon the recent developments of non-stationary factor models. The decision to do so was primarily driven by the above-mentioned statistical evidence and the fact that the aim is to get an index that captures the level of financial stress rather than the change in financial stress. By differentiating the data, the information content of the indicators changes, which is undesirable (e.g. Harmonic distance gives information about the tendency among banks to focus on repayment of current loans, while the first difference of this variable captures the change of this effect which, while informative, captures a different effect).

The FISS utilises standardised time series data which are often autocorrelated and persistent, thus dynamic effects must be considered. This is underpinned by the unit root tests (see Appendix 2) showing the importance of dynamics in the data set. Although not all of the chosen variables portray non-stationary tendencies, this is not a problem, as the factors that are gained all have unitroot tendencies and as such can be explained well with a random walk structure. 
Furthermore, the algorithm is capable of handling scenarios where some factors are stationary while the others are not (Eickmeier, 2005). Additionally, Sims (1988) and Uhlig (1994) argue that Bayesian procedures are simpler and often more reasonable in the presence of unit roots, as they avoid the drawbacks that arise due to classical distribution theory. This underpins the choice of using a Bayesian DFM.

Although applying dynamics to a factor model is enticing, it is not costless: orthogonality of factors, information on explained variance and factor interpretability are given up. These caveats have to be kept in mind when creating a DFM, as each aspect carries different consequences. The lack of orthogonality of factors means that special care has to be taken when multiple factors are obtained. If the factors are too correlated, there is a possibility that the added factors do not yield additional information. Giving up information about explained variance is costly because it makes aggregating multiple factors into one comprehensive index a non-trivial task. Sacrificing factor interpretability means that it is hard to determine what each factor captures. In a DFM, the common behaviour of a high dimensional vector of time series variables is described by a few latent dynamic factors together with a vector of zero mean idiosyncratic disturbances. The idiosyncratic noise term arises from measurement error and from specific features of the individual data series. The latent factors usually follow a VAR structure of lag order $p$. This is shown in equations (3) and (4) below:

$$
\begin{aligned}
y_{i t} & =\lambda_{i 0}+\lambda_{i} f_{t}+\varepsilon_{i t} & \varepsilon_{i t} \sim N\left(0, \sigma_{i}{ }^{2}\right), \\
f_{t} & =\sum_{i=1}^{p} \phi_{i} f_{t-i}+\varepsilon_{t}^{f} & \varepsilon_{t}^{f} \sim N\left(0, \Sigma^{f}\right) .
\end{aligned}
$$

Equation (3) is the observation equation signifying that each vector $y_{i t}$ can be described by independent regression $i$. The disturbance term of this equation, $\varepsilon_{i t}$, is assumed to be independent and identically distributed (i.i.d.). The FISS uses a simplified version of the DFM, since the possible AR structure of these disturbance terms is ignored (see Koop and Korobilis, 2010).

Equation (4) plays the role of the state equation, describing the structure of the latent factors. In the FISS, the vector of latent factors follows a VAR structure. The disturbance term of the state equation, $\varepsilon_{t}^{f}$, is assumed to be i.i.d. In most cases, $\Sigma^{f}$ is a diagonal, and for the model presented in this paper this condition is fulfilled. One last assumption is that the two disturbance terms, $\varepsilon_{t}^{f}$ and $\varepsilon_{i t}$, are independent of each other.

This system of equations turns out to be a regular form of a state space model. This is an important observation because it allows the application of the CarterKohn algorithm (see Carter and Kohn, 1994) to draw factors. Furthermore, all 
methods for posterior simulation for state space models are available, due to the model's following the structure described above.

\subsection{The choice of the factors and the estimation of the common stochastic trend}

The first problem to be addressed is the choice of the number of factors. There are two main guidelines on how to choose the optimal factor structure: the first is to find the statistically optimal factor set (see Bai and $\mathrm{Ng}, 2002$; Lopes and West, 2004), the other is to predefine the number of factors based on intuition or empirical aspects (see Engle and Watson, 1981). When choosing the number of factors, the authors tried to merge the two ideas and four factors were chosen. As described in Section 2, the indicators were categorised by the financial market they represent. On account of this, the intuitive number of factors would be the number of categories constructed. The ultimate goal of the FISS is to capture as much information from the different sources of financial stress as possible, and four factors satisfy this goal, with an explained variance of around $85 \%{ }^{6}$ Furthermore, these factors are not highly correlated, which highlights how they capture different aspects of financial stress.

Section 2 showed that it is very common for a factor methodology based FSI to use only the first factor. This was unfeasible for the FISS, as using only one factor captured a mere $55 \%$ of the total variance in the data. This low explanatory power would have violated the first guideline mentioned above.

The second problem that had to be tackled is the persistence of the dataset. The factors in the model are estimated, following Bai (2004), as so-called stochastic trends: non-stationary dynamics are allowed in the state equation. In this way, the model can fully capture the information contained in the financial data. Nevertheless, it is imperative to check the relations between the factors to avert any spurious regressions in the model.

Table 2. Coefficient matrix of the state equation

\begin{tabular}{|c|c|c|c|c|}
\hline & $\mathbf{F 1}$ & $\mathbf{F 2}$ & $\mathbf{F 3}$ & $\mathbf{F 4}$ \\
\hline $\mathbf{F} \mathbf{t}_{\boldsymbol{t}-\mathbf{1}}$ & 0.989 & 0.009 & 0.003 & 0.001 \\
\hline $\mathbf{F} \mathbf{t}_{\boldsymbol{t}-\mathbf{1}}$ & -0.001 & 1.001 & 0.002 & -0.007 \\
\hline $\mathbf{F} \mathbf{3}_{\boldsymbol{t}-\mathbf{1}}$ & -0.012 & 0.029 & 0.976 & -0.016 \\
\hline $\mathbf{F} \mathbf{t}_{\boldsymbol{t}-\mathbf{1}}$ & 0.005 & -0.016 & 0.018 & 1.004 \\
\hline
\end{tabular}

Table 2 shows the coefficients of the state equation matrix. This matrix is close to a unit matrix, which highlights how the factors of the model behave

\footnotetext{
${ }^{6}$ Explained variance for the model was obtained from principal component analysis before applying dynamics to the system.
} 
like independent random walks. This simple structure makes it unnecessary to deal with the possible linkages between the factors such as cointegration (see Banerjee et al., 2014). On the other hand, it has to be noted that the predictive power of a model described by such dynamics is very limited. Thus, the expansion of this modelling framework in the direction of a forecasting approach is not straightforward.

\subsection{Bayesian model specification}

As mentioned before, due to the regular state-space form of the FISS, the standard algorithms can be used to draw factors. The observation equations conditional on the factors are just normal linear regression models, which are independent from each other. Thus, simulating the equations one by one is possible.

An identification issue arises when applying the PCA type factor model as a starting point: the matrix of factor loadings and factors is unique only if rotations are ruled out. One way of surmounting this issue is imposing restrictions on the loadings (see Lopes and West, 2004). As such, the matrix of the loading was transformed in a block lower triangular form with strictly positive elements in the main diagonal. After performing this transformation, the simulation procedure can commence without any problems. The Carter and Kohn algorithm was used to draw factors, using a Gibbs sampler to simulate the parameters: $\sigma_{i}^{2}, \Sigma^{f}, \lambda_{i 0}, \lambda_{i}, \phi_{j}$.

The prior for the coefficients in the observation equations is a normalinverse gamma, and the elements of $\Sigma$ are inverse gamma. Since the observation equations are independent, the posterior parameters $\sigma_{i}^{2}, \lambda_{i 0}$ and $\lambda_{i}$ can be simulated separately in the $i$-th dimension (see Geweke and Zhou, 1996). The matrix of factor loadings is normally distributed with restrictions on the block structure of the matrix and with positive, truncated normally distributed elements in the diagonal.

The prior for the state equation is normal-inverse Whishart. The state equation is in a VAR form, so the Gibbs sampler with no Metropolis-Hastings steps can be applied (see Kadiyala and Karlsson, 1997).

The prior selection is supported by Uhlig (1994), where it is stated that in the presence of a unit root the choice of a Normal-Wishart prior centred at the unit root yields the best results.

The number of simulations run was set at 10000 with a burn-in of 2000 and a thin value of 7 . This was done to get the most accurate estimates for the factors. Detailed evaluation of the convergence of the algorithm used is discussed in Appendix 6. The factors obtained with these specifications are shown in Figure 2. 
Figure 2. Factors of the FISS

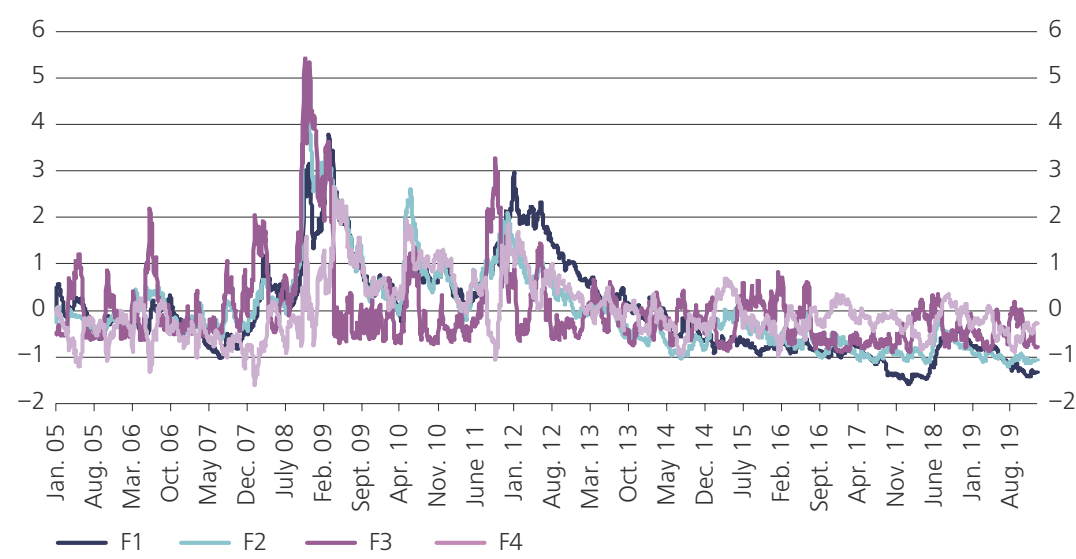

Several things can be observed in Figure 2. First of all, the factors can take on a negative value, and the factor level values range from -2 to +5.5 . Although not necessary, it is useful to convert the final FISS to a range between 0 and 1 . This was achieved by shifting each factor up by 2 . After the factors were aggregated (more on this in Section 4.4), the index values were divided by the historical maximum, giving the final FISS. It has to be emphasised that these transformations are not necessary, the factors are informative without them, and they were only done so the final index was on a scale between 0 and 1 . Another important feature of the factors is that they seem to be correlated during certain periods. This is important because we expect multiple financial markets to show signs of instability during periods of high systemic stress.

\subsection{Aggregation of the factors}

Aggregating the factors into a single index is not trivial. As mentioned before, the factors in question are not orthogonal, and due to this, using the common practice in principal component analysis, namely the usage of the square root of the eigenvalues as weights, is not possible. On account of this, a handful of aggregation methods were tested: unweighted average, weighted average where the weights are obtained using information value (IV) methodology, weighted average where the weights are obtained from $\mathrm{QR}$, and weighted average where the weights are simulated with no prior information imposed.

\section{Unweighted average}

While the simplicity of the unweighted average is appealing, that is not its only strength. The primary reason considered is that no ex-ante assumption about when the index should peak or about what variables it should interact with are required. Nevertheless, there is a drawback associated with aggregation 
using unweighted averages: it implicitly assumes that all factors are equally informative. The validity of this assumption depends on whether the alternative weighting schemes produce different dynamics in the FISS. These considerations make the unweighted average a good benchmark to compare the alternative weighting systems.

\section{Weighted average using quantile regression}

The reasoning behind using QR to get weights is motivated by the fact that certain factors may be more informative about financial stress than others. This can be measured by the factors' effects on IP. Following the intuition of De Bandt and Hartmann (2000), the information content of the factors, in relation to the real economy, is contained in their extreme values. As such, a quantile regression measures the interaction between the tail events of the factors and the IP. Nevertheless, there are drawbacks to utilising a QR. First of all, the IP is recorded only monthly, while the FISS is recorded daily. Conversion of the FISS is not an issue, but there is an undeniable loss of information in doing so. Furthermore, IP is a non-stationary process by definition. As such it has to be differenced along with the factors to utilise QR, which further depresses the information content of the factors obtained. ${ }^{7}$ In addition, the aim of the FISS is to be a thermometer of stress and tying its weighing too closely to the tail events of IP can also lead to loss of information. For more information on the methodology see Appendix 4.

\section{Weighted average using information value}

The next methodology considered is the IV, which is widely used to measure the separation power of a variable in creating PD and LGD models (Siddiqi, 2012). The approach relies on the variable indicating a problem at the right time, so in the case of an FSI, whether the indicator gives high values in bad times and low values in good times. Using the IV methodology has the benefit of no conversions being required like in the previous scenario. Furthermore, the IV is not restricted to the IP and as such no information is lost about financial markets that did not have much effect on the real economy. However, this comes at the cost of having to define crisis and evaluation periods ex-ante to measure the ratio of good and bad signals. A further drawback is that bins need to be manually defined after checking the ratio of good and bad observations in each decile. These introduce ad-hoc elements to the weighting structure which can bias the final FISS to represent preconceptions about financial stress episodes in the market. For more information on the methodology see Appendix 5.

\footnotetext{
${ }^{7}$ Only the weights from the 99th quintile estimates are used, as the slope coefficients are most likely to be different from 0 for this quintile only. It has to be noted that the sign of the coefficients is the opposite of the expected sign; as such the QR is only presented for illustrative purposes.
} 


\section{Simulated weights}

Finally, weights were also simulated without imposing any prior information about the distribution of the draws. As such, a simplex method was created to get an estimate for all possible weight combinations. In total, 18,500 potential weight pairings were calculated. The aim of this exercise was to check the sensitivity of the final index in regards to the weighting. Furthermore, it has information about how much information the other weighting methods add compared to this uninformed simulation. Only the middle $80 \%$ of combinations is presented so as to maintain reasonable bands around the benchmark estimate.

\section{Comparison of results}

Table 3 shows the weights gained from the different estimations. It has to be noted that, because the QR method utilises differenced data and yields slope estimates close to zero, it is only shown for completeness (for more information see Appendix 4 and footnote 7). One striking feature is that the weights are very close to the unweighted benchmark case, with the IV method portraying the biggest deviation from it for the fourth factor.

Table 3. Weights gained by the different estimation procedures, $\%$

\begin{tabular}{|c|c|c|c|c|}
\hline & F1 & F2 & F3 & F4 \\
\hline Unweighted & 25.00 & 25.00 & 25.00 & 25.00 \\
\hline QR & 37.46 & 21.53 & 11.70 & 29.32 \\
\hline IV & 25.81 & 45.07 & 27.47 & 1.65 \\
\hline
\end{tabular}

The FISS with the weights of Table 3 are shown in Figure 3. All indices were transformed onto a $[0,1]$ scale as described in Section 4.3. From this figure it can be seen that the different weights do not change the index very much. The figure reinforces the findings of Table 3 that the different weight estimations do not result in significantly different indices. There is no real way to determine which version represents reality the best with such small differences. On account of this, the unweighted average will be used for the remainder of the paper.

Furthermore, the bands around the average estimate show that the possible weight combinations do not diverge from the average estimate very much during periods when the index increases suddenly and dramatically. The fact that the 'confidence' band around the average is existent is further proof of the factors' capturing different aspects of financial stress, while the observation that the bands become extremely narrow during sudden increases highlights how the aggregation of the factors yields a good measure of systemic stress. Additionally, this gives further justification for the usage of the simple average as an aggregation method. 
Figure 3. Weighted and unweighted averages of the FISS

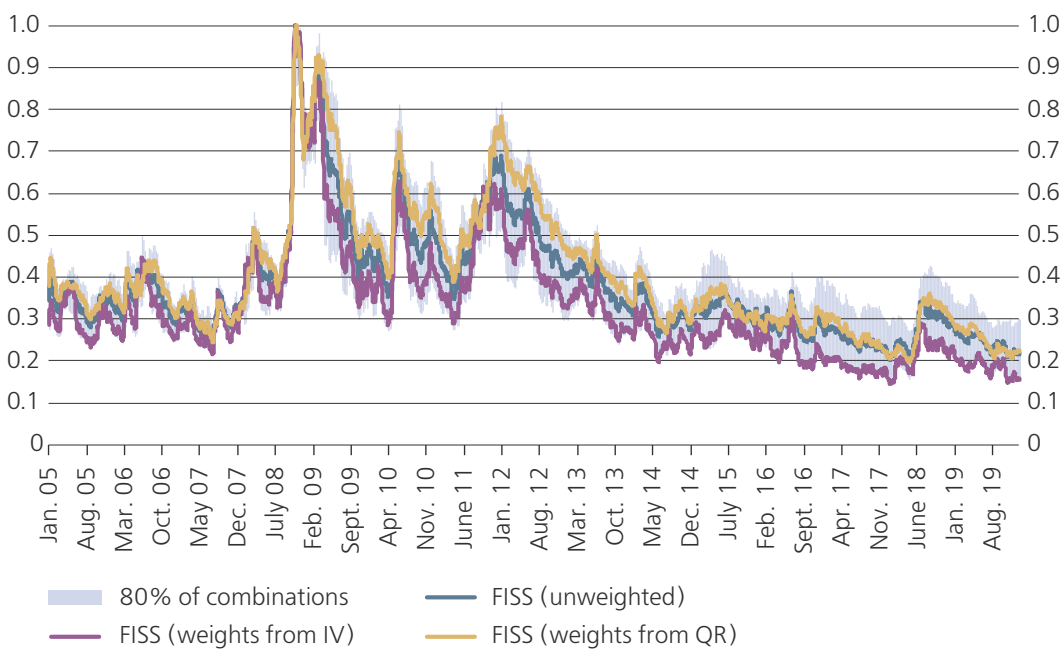

Figure 3 also portrays how, due to the dynamic nature and the Bayesian methodology, the index can reach high levels quickly, while it takes a longer time for it to decrease. From a policy maker perspective, this property is important, as it decreases the probability of the index breaching levels that signal crisis levels of stress only for this level to disappear the following week. One interesting observation from the figure is that the volatility of the index seems to portray heteroscedastic tendencies. Accounting for this could be a further improvement to the FISS.

\section{Results}

\subsection{Performance of the index}

Having an objective, empirical way to determine the performance of the FISS is difficult. Measuring financial stress means that the FISS has to reflect all material disturbances in the financial sector, irrespective of whether the connected risks materialise in the real economy. Thus, the only objective, numeric measures of FISS would be the very indicators it aggregates.

Following Holló (2012), Hakkio and Keeton (2009) and Holló et al. (2012), the performance of the constructed index is verified by whether its peaks match up with events of importance for the financial markets. Due to the large size of the dataset ( $\mathrm{T}=3126$ after adjustments, 3 January 2005 - 30 June 2017), the index is broken down into two subsamples for this Section: one from 2005 until 2010, shown in Figure 4; and the other from 2010 until 2017, shown in Figure 5. Furthermore, the two figures were each broken down into two periods. Two periods of Figure 4 are the events before the Global Financial Crisis (hereinafter GFC; January 2005 - September 2008) and the GFC (September 2008 - 
March 2010). Two periods of Figure 5 are the European sovereign bond crisis (March 2010 - September 2013) and the period encompassing the post-crisis events (September 2013 - February 2017).

Figure 4. Values of the FISS to 28 February 2010

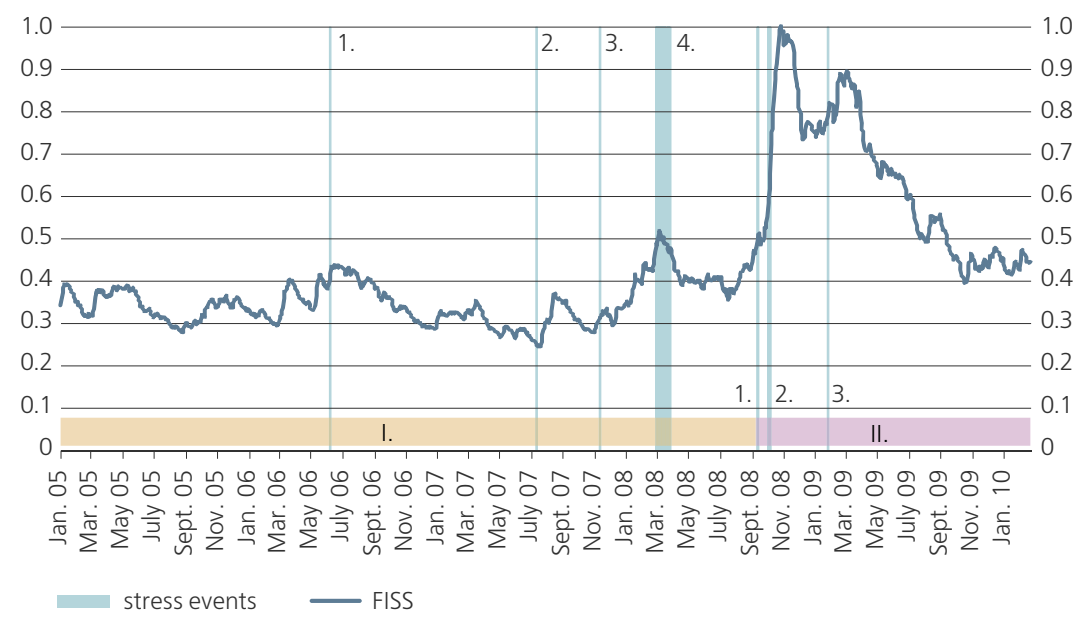

I./1: Introduction of the fiscal austerity package in Hungary on 12 June 2006. The FISS starts to increase a month before the programme was announced, due to markets expecting that some austerity measures would be introduced, but the type and severity of the measures were unclear. This increased uncertainty in the markets lead to the FISS increasing sharply during May and June.

I./2: Bear Sterns announces two of its subprime hedge funds lost all value on 16 July 2007. This announcement can be viewed as the start of the subprime debacle that eventually led to the collapse of Lehmann Brothers. This announcement increased both information asymmetry and uncertainty in the financial markets. Following this date, the FISS's value increases as capital markets and foreign exchange markets reacted to the news. The third event in Figure 4 (I./3) was also about Bear Sterns: On 15 November 2007, Standard \& Poor's downgraded the investment bank amid concerns for its solvency.

I./4: Turbulence in the Hungarian government bond market during March 2008. Although Hungarian banks did not have large exposures to Mortgage Backed Securities (hereinafter MBS), the decreased risk appetite of international traders narrowed Hungary's opportunities to access funding, raising the price of funds. This effect was amplified as the government bond market came under selling pressure as there were concerns about their financing due to deteriorating macroeconomic fundamentals. These events are captured in the FISS, as its level rose sharply during the month. Although the index value drops off after the month, the aftermath is higher levels of stress, as the underlying fundamentals 
did not improve. The fact that the model is able to capture this persistence in uncertainty is partly due to the dynamic structure, and it yields a more intuitive picture of how market participants internalise such events.

II./1: Bankruptcy of Lehmann Brothers on 15 September 2008. The following day, Moody's and Standard \& Poor's downgraded the ratings of AIG due to concerns about the compounding losses of MBS, which triggered fears that the company may be insolvent. These events generated widespread uncertainty in the financial markets. The aftermath was the deepening of the GFC, which led to a sudden spike in the FISS. Concerns in regards to the solvency of holders of unhedged foreign-currency-denominated debt, as well as concerns about the stability of the overall banking system lead to further fears about the financing of the Hungarian economy. This was further worsened by the fact that 6-10 October (the sixth event in Figure 4; II./2) was the worst week for the stock market in the United States in 75 years (the Dow Jones dropped $22.1 \%$, while the S\&P 500 dropped 18.2\%). The aftermath of these events led to the FISS recording its highest level, as uncertainty increased leading to traders shifting their preferences around the globe, flocking to safer investment options (flight to quality). The value of the FISS eventually dropped off as Hungary signed the credit-line agreement with the IMF in late October. Nevertheless, the level of stress did not reach pre-Lehmann levels.

II./3: Turbulence in the Hungarian foreign exchange spot market during January 2009. During this turbulence, the EUR/HUF exchange rate breached the 300 level, eventually reaching a value of 316 on 6 March of the same year. This was coupled with increased volatility in the spot market, which led the FISS to spike in values momentarily. This increased volatility also affected the Hungarian banking system due to its large exposure to holders of foreign-currency-denominated debt, whose solvency came under heavy scrutiny.

III./ 1: Downgrade of Greece to junk bond category by Standard \& Poor's on 27 April 2010. Portugal was also downgraded on the same day, but it kept its investment grade status. This event is the first in Figure 5 and can be viewed as the start of the euro area sovereign debt crisis. Furthermore, there was uncertainty surrounding the newly formed Hungarian government. There were statements comparing the situation of Hungary to Greece, which unsettled markets (see article published on portfolio.hu: "Kósa: "szük esélyünk van arra, hogy elkerüljük Görögország helyzetét"”, 2010). The value of the FISS rises, as it captures this increased uncertainty through the increased volatility in the exchange rate market and the government bond market.

III./2: Turbulence in the Hungarian foreign exchange swap market during December 2010. This turbulence was mainly driven by the foreign-currencydenominated debt problem's not having been adequately addressed. Furthermore, the government introduced several new policies to stabilise government debt. The market reacted to these events through the government debt market. Coupled 
with the increased uncertainty of the euro area causing exchange rate volatilities to rise, these issues caused the FISS to increase.

III./3: Standard \& Poor's raises the possibility of downgrading Italy on 21 May 2011. This had a profound impact on the FISS as some Italian banks have subsidiaries in the Hungarian market that are systemically important. As the PD of these banks increased, the FISS started to climb gradually, signifying the increased uncertainty in the interbank market.

Figure 5. Values of the FISS from 1 March 2010

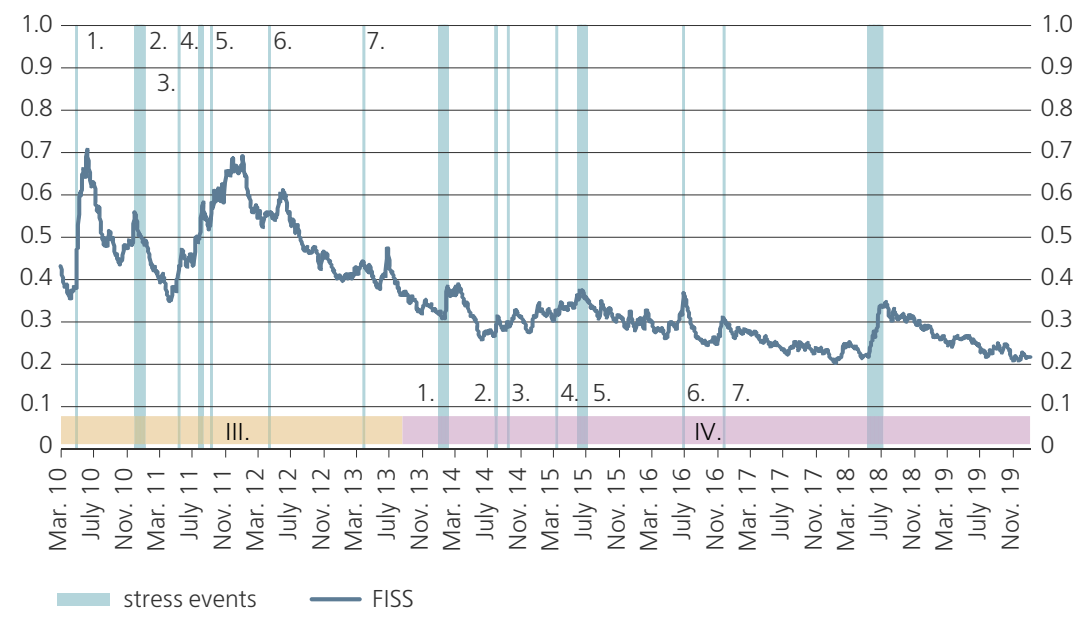

III./4: Euro area sovereign debt problem worsens in mid-July of 2011. During this time, Greece was downgraded further by Standard \& Poor's to speculative grade on 27 July 2011. Furthermore, Standard \& Poor's announced that it would closely monitor the sovereign debt process of the United States on 25 July 2011, eventually downgrading the United States on 5 August 2011. This caused investors to scramble to perceived safe-haven assets, such as Swiss bonds (flight to quality). This had the effect of increasing the CHF/HUF exchange rate to a level of 230. Apart from the increased volatility in the exchange rate market, this further impaired Swiss franc-denominated debt holders' position. This increased concerns about the solvency and liquidity of Hungarian banks. The increase in the FISS is attributed to turbulence in the foreign exchange market and the government bond market.

III./5: Government announces plans related to early repayment of foreigncurrency-denominated loans at a fixed exchange rate on 9 September 2011. This was done to tackle the concerns about the solvency of these debtholders. This announcement increased the FISS as it forced the Hungarian banking system to absorb the losses that arose from the early repayment of the loans at a non-market exchange rate. The final payment opportunity was open until February 2012. 
The programme cost the Hungarian banking system over HUF 250 billion (see article published on portfolio.hu: 'Vége a végtörlesztésnek', 2012). This increased the PD of all banks and led to an uptick in the FISS.

III./6: Papademos resigns on 11 April 2012. After reaching a post-Lehmann peak in January 2012, the index starts to gradually decrease as the financial markets of Europe seemed to stabilise. This tendency halted when concerns about the solvency of Greece re-emerged. The resignation of the Prime Minister of Greece L. Papademos further intensified these concerns, making the FISS rise as uncertainty on the financial markets increased. The increased uncertainty occurred in the government bond market and the foreign exchange market.

III./7: Cypriot financial crisis during March 2013. There was a slight uptick in the FISS during this time, but the Cypriot financial crisis was dealt with swiftly. Furthermore, the Hungarian financial system did not have exposures to Cyprus, and the uptick in the FISS is mostly due to the increased exchange rate volatility.

IV./1: Hungarian government bonds come under selling pressure during January 2014. This selling pressure came from Templeton drastically decreasing its holdings of Hungarian government bonds. This selling pressure affected the risk premium charged on Hungarian government bonds, leading to a slight uptick in the FISS.

The next two events are the economic sanctions imposed on Russia by the EU on 29-31 July 2014 (IV./2) and 9 September 2014 (IV./3). These sanctions were met with Russian embargos on imports from the EU. Since Hungary had export exposure to Russia in agricultural goods, these countermeasures hurt the general economy of Hungary, raising the FISS moderately as the foreign exchange market, capital markets and the government bond market reacted to the news.

IV./4: The start of the Quaestor debacle on 10 March 2015. The core of the breakdown was the revelation that Quaestor operated with fictitious bonds: of the HUF 210 billion bond stock, HUF 150 billion was issued without permission. This event increased the information asymmetry in the Hungarian financial system (especially in the interbank market), which increased the FISS gradually until the summer of 2015.

IV./5: Greek debt repayment debacle in June 2015. Tsipras announced a referendum on the bailout agreement, which the Greek parliament approved on 28 June 2015. Furthermore, capital controls were imposed, and the Greek banks were forced to close on account of a lack of liquidity and remained closed until 20 July 2015 . These events increased the volatility of the euro, which resulted in a local maximum in the FISS.

The final two events on Figure 5 are the Brexit vote on 23 July 2016 (IV./6) and the US presidential election results on 23 November 2016 (IV./7). These last two events are minor in terms of their effects on the Hungarian financial markets, and the upticks are due to the increased volatility in the exchange rate of the euro and British pound on the first of these events, and the US dollar on the latter. 


\section{IV./8 shows a moderate increase in the stress index over a period of a few} months in 2018Q2. This was on account of the lower risk appetite of investors which led to the yields on government bonds gradually increasing. The FISS captures this reduced risk appetite by a gradual increase in its value over the course of a month. The markets stabilised by the end of the quarter, and from the start of 2018Q3 the FISS starts to gradually drop. Although, the increase in Figure 5 looks stark, the value of the FISS never reached the heights it had during the financial crisis.

Table 4. Ranking the effects of the events on the FISS

\begin{tabular}{|c|c|c|c|c|c|c|c|c|c|c|}
\hline \multicolumn{3}{|c|}{ Event } & \multicolumn{2}{|c|}{ Minimum } & \multicolumn{2}{|c|}{ Maximum } & \multicolumn{2}{|c|}{ Change } & \multicolumn{2}{|c|}{ Rank } \\
\hline Number & Source & Anticipation & Date & Value & Date & Value & In $\%$ & Raw & $\begin{array}{c}\text { By \% } \\
\text { change }\end{array}$ & $\begin{array}{l}\text { By raw } \\
\text { change }\end{array}$ \\
\hline I./1 & $\mathrm{HU}$ & Yes & 09-May-06 & 0.33 & 15-Jun-06 & 0.43 & 30.46 & 0.1009 & 9 & 12 \\
\hline I. $/ 2$ & US & No & 16-Jul-07 & 0.25 & 17-Aug-07 & 0.37 & 48.42 & 0.1209 & 4 & 7 \\
\hline I. $/ 3$ & US & Yes & 31-Oct-07 & 0.28 & 27-Nov-07 & 0.33 & 19.47 & 0.0544 & 15 & 16 \\
\hline I. $/ 4$ & $\mathrm{HU}$ & No & 18-Feb-08 & 0.42 & 10-Mar-08 & 0.52 & 21.91 & 0.0931 & 13 & 13 \\
\hline II./1 & US & Yes & 18-Jul-08 & 0.36 & 17-Sep-08 & 0.51 & 42.25 & 0.1517 & 5 & 4 \\
\hline II./2 & US & Yes & 26-Sep-08 & 0.50 & 31-Oct-08 & 0.99 & 96.70 & 0.4861 & 1 & 1 \\
\hline II./3 & $\mathrm{HU}$ & No & 09-Jan-09 & 0.76 & 12-Mar-09 & 0.87 & 14.90 & 0.1130 & 17 & 10 \\
\hline III./1 & $\mathrm{HU} / \mathrm{EU}$ & Yes & 13-Apr-10 & 0.37 & 09-Jun-10 & 0.69 & 85.27 & 0.3172 & 2 & 2 \\
\hline III./2 & $\mathrm{HU}$ & Yes & 05-Oct-10 & 0.43 & 01-Dec-10 & 0.56 & 28.09 & 0.1217 & 10 & 5 \\
\hline III./3 & $\mathrm{EU}$ & No & 11-Apr-11 & 0.35 & 25-May-11 & 0.47 & 34.96 & 0.1218 & 7 & 6 \\
\hline III./4 & EU/US & No & 11-Jul-11 & 0.47 & 10-Aug-11 & 0.58 & 24.71 & 0.1149 & 12 & 9 \\
\hline III./5 & $\mathrm{HU}$ & No & 01-Sep-11 & 0.52 & 01-Dec-11 & 0.68 & 30.88 & 0.1615 & 8 & 3 \\
\hline III./6 & $\mathrm{EU}$ & Yes & 20-Mar-12 & 0.52 & 01-Jun-12 & 0.61 & 16.52 & 0.0866 & 16 & 14 \\
\hline III./7 & $\mathrm{EU}$ & No & 13-Feb-13 & 0.40 & 26-Mar-13 & 0.44 & 9.16 & 0.0370 & 22 & 20 \\
\hline IV./1 & $\mathrm{HU}$ & No & 17-Jan-14 & 0.31 & 13-Mar-14 & 0.39 & 24.93 & 0.0771 & 11 & 15 \\
\hline IV./2 & EU/RU & No & 29-Jul-14 & 0.27 & 12-Aug-14 & 0.31 & 13.29 & 0.0362 & 18 & 21 \\
\hline IV./3 & EU/RU & No & 09-Sep-14 & 0.29 & 20-Oct-14 & 0.32 & 10.24 & 0.0298 & 21 & 22 \\
\hline IV./4 & $\mathrm{HU}$ & No & 10-Mar-15 & 0.33 & 08-Jun-15 & 0.37 & 12.69 & 0.0414 & 20 & 19 \\
\hline IV./5 & $\mathrm{EU}$ & Yes & 22-Apr-15 & 0.33 & 16-Jun-15 & 0.37 & 13.01 & 0.0427 & 19 & 18 \\
\hline IV./6 & $\mathrm{EU}$ & Yes & 19-Apr-16 & 0.26 & 27-Jun-16 & 0.37 & 40.39 & 0.1057 & 6 & 11 \\
\hline IV./7 & US & Yes & $26-$ Oct-16 & 0.25 & 25-Nov-16 & 0.30 & 21.73 & 0.0537 & 14 & 17 \\
\hline IV./8 & $\mathrm{HU}$ & Yes & 11-May-18 & 0.22 & 27-Jun-18 & 0.34 & 55.45 & 0.1204 & 3 & 8 \\
\hline
\end{tabular}

In order to evaluate the effectiveness of the FISS, a summary table was created (see Table 4) highlighting the events causing a material change in the index. Here the effects are categorized by their having an anticipation period, in other words whether the event came as a surprise or not, and the geographical source of the disturbance. The first striking feature is that there appears to be no difference in the movement of the index with respect to the source of the disturbance. This is reassuring, as the aim of the model is to capture financial stress regardless of the source of the event.

It has to be noted that market anticipation only matters because the events shown are imperfect proxies of stress events. The announcement of 
the Hungarian government's austerity programme (I./1) did not happen in a vacuum, for example: market participants had already started to react to the worsening financials of the Hungarian government. As such, the true start of the stress period is not the announcement, but when the financial markets started to react to the worsening economic fundamentals in Hungary. However, this start of the event is impossible to determine ex-ante. In Table 4 the start of the anticipation was determined as the minimum point in the FISS around the marked event.

An interesting question is whether the FISS should be interpreted on a log scale. As noted before, looking at the FISS, the value seems to be more volatile the higher the level of the index. This could be due to functional misspecification. Table 4 tries to tackle this concern by looking at the change in the index at the events portrayed in the previous Section and ranking them by raw as well as percent change. From the table, it can be seen that the percent change ranking puts too much weight on the changes occurring at the end of the sample as opposed to the events that occurred during high stress periods. As such it can be concluded that there is no functional form misspecification and that the FISS is informative in raw levels. This is further supported by the fact that the included variables were kept in raw form and were not converted to log form.

\subsection{Robustness}

The FISS is not run recursively, thus it is important to make sure that the model does not change drastically as more data is added to the sample. To test this, the model was re-run on several sample sizes to verify that the peaks of the model capture the important stress events of the Hungarian financial markets in levels, while capturing the minor events in dynamics. Figure 6 shows the results of this robustness test. The following sample sizes were tested: the FISS with the last 500 observations not taken into account, the last 1500 observations not taken into account, the FISS with the first 500 observations not taken into account, and the FISS with the first 1500 observations not taken into account.

Inspection of Figure 6 reveals that the estimates are extremely robust when observations are taken off the end of the sample. The dynamics match up almost identically and the difference in the levels is minimal. This level of robustness is maintained also when the first 500 observations are taken off the estimation sample. The only subsample where the model yields somewhat different results is when the first 1500 observations are ignored. This is due to the fact that the biggest shock in the data, the 2008 crisis, is not accounted for in this set up, and as such the factor identification for financial stress is hindered. However, even with this caveat the model performs admirably in the given subsample. 
Figure 6. The FISS on different sample sizes

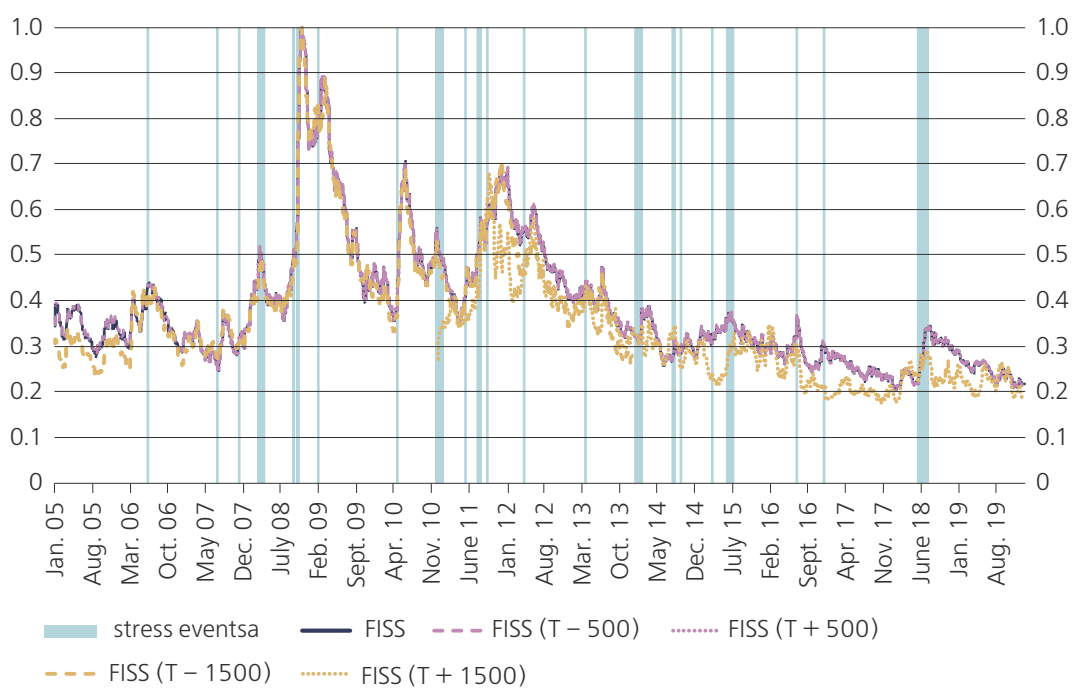

Note: for scaling the $(T+1500)$ series the maximum of the full-length estimation was used.

This level of robustness is partly attributed to the Bayesian structure of the model: even when almost half of the sample is not taken into account, the model reaches its historic maximum in the same week. It is possible to create a recursive variant of the FISS, but Figure 6 shows that it is not necessary, as the model correctly identifies the underlying factors of financial stress.

\section{Conclusion}

This paper presented the FISS as a measure of financial stress in the Hungarian financial system. This FSI aims to capture the financial instabilities in the four core segments of the financial system: the foreign exchange market, the interbank and bank segment, the government bond market, and the capital market. In total, 19 variables were used across the four segments, compressed into four common stochastic trends.

To aggregate the four factors, different weight estimation procedures were tested, namely a quantile regression, information value as well as a simulation method. It was found that the simple average yields satisfactory results and the more complex methods do not increase the information content of the FISS.

The time-varying methodology of the factors allows the compositions of the underlying common stochastic trends to change as the financial markets further develop. Nevertheless, as the financial market of Hungary deepens, the indicators of the FISS should be revisited to make sure the data selection reflects the underlying structure of the financial system. 
The FISS is capable of capturing the core dynamics of financial instability on the Hungarian financial markets and will be a useful FSI for future policy use. As such, the FISS has been part of the broader macroprudential toolkit of the Hungarian Central Bank since August 2017. During this time, the index has proven to be sensitive enough to give information about financial stress, without being too sensitive and giving false positives. As such, the proposed methodology meets the aim presented in the beginning of the paper: it creates a sufficiently sensitive measure of financial risk for an economy that lacks deep derivative markets.

The FISS fits in the countercyclical capital buffer (CCyB) framework of the macroprudential toolkit. As opposed to the widely used early warning indicators, the FISS provides information about the current level of tension in the financial system of Hungary, acting as a thermometer of stress and making it particularly useful when a decision has to be made about the release of the CCyB. The FISS provides crucial information when releasing the $\mathrm{CCyB}$, as the best practice is to release built-up capital promptly to make sure the banking sector has enough capital to cushion the impact of financial stress (Detken et al., 2014). The CCyB is built up over a period of two years, so a precise signal about the current financial stress is important, because an erroneous release of the buffer is costly. The FISS satisfies the condition of being a good variable for the release of the $\mathrm{CCyB}$ as it only reaches extreme heights during the 2008 global financial crisis. Additionally, since the FISS is a continuous variable, it is capable of giving information about periods that portray only moderate levels of financial stress, such as the European bond crisis of the 2010s.

Policy evaluation is another important aspect of central banking. Having a better understanding of how effective monetary policy is in normal times and times of stress helps tune the interest rate setting of the Central Bank. The continuous nature of the FISS allows it to be a threshold variable in bigger VAR models that try to capture the dynamics of the economy across stress and normal regimes. As such the FISS is a useful tool, not only in the CCyB framework, but is also useful as a threshold variable for policy tuning and evaluation.

One potential area of improvement to the FISS stems from the data and the factors portraying significantly higher volatility during times of financial stress, or more precisely, the heteroscedastic features. It follows that the model can be extended and improved by accounting for these innovations. Del Negro and Otrok (2008) outline such an approach: using time-varying parameters and stochastic volatility in both the factors and the loadings, the heteroscedastic features of the factors can be tamed. 


\section{References}

Akhtar, M. and Hilton, R. S. (1984). Effects of Exchange Rate Uncertainty on German and U.S. Trade. Federal Reserve Bank of New York Quarterly Review, 9(1), pp. 7-16.

Bai, J. (2003). Inferential Theory for Factor Models of Large Dimensions. Econometrica, 71(1), pp. 135-171. doi:10.1111/1468-0262.00392

Bai, J. (2004). Estimating Cross-Section Common Stochastic Trends in Nonstationary Panel Data. Journal of Econometrics, 122(1), pp. 137-183.

Bai, J. and Ng, S. (2002). Determining the Number of Factors in Approximate Factor Models. Econometrica, 70(1), pp. 191-221. doi:10.1111/1468-0262.00273

Banerjee, A., Marcellino, M. and Masten, I. (2014). Forecasting with Factor-Augmented Error Correction Models. International Journal of Forecasting, 30(3), pp. 589-612.

Barigozzi, M., Lippi, M. and Luciani, M. (2020). Cointegration and Error Correction Mechanisms for Singular Stochastic Vectors. Econometrics, 8(1), 3.

Bernanke, B. S. and Boivin, J. (2003). Monetary Policy in a Data-Rich Environment. Journal of Monetary Economics, 50(3), pp. 525-546.

Bernanke, B. S., Boivin, J. and Eliasz, P. (2004). Measuring the Effects of Monetary Policy: a Factor-augmented Vector Autoregressive (FAVAR) Approach. NBER Working Papers, N 10220.

Boivin, J. and Ng, S. (2006). Are More Data Always Better for Factor Analysis? Journal of Econometrics, 132(1), pp. 169-194.

Caballero, R. J. and Krishnamurthy, A. (2008). Collective Risk Management in a Flight to Quality Episode. The Journal of Finance, 63(5), pp. 2195-2230. doi:10.1111/j.1540-6261.2008.01394.x

Caballero, R. J. and Kurlat, P. D. (2008). Flight to Quality and Bailouts: Policy Remarks and a Literature Review. MIT Department of Economics Working Paper, N 21.

Carter, C. K. and Kohn, R. (1994). On Gibbs Sampling for State Space Models. Biometrika, 81(3), pp. 541-553.

Cevik, E. I., Dibooglu, S. and Kutan, A. M. (2013). Measuring Financial Stress in Transition Economies. Journal of Financial Stability, 9(4), pp. 597-611.

Crosbie, P. and Bohn, J. (2003). Modeling Default Risk. Moody's KMV Company Technical Paper.

De Bandt, O. and Hartmann, P. (2000). Systemic Risk: A Survey. ECB Working Paper, N 35.

Del Negro, M. and Otrok, C. (2008). Dynamic Factor Models with Time-Varying Parameters: Measuring Changes in International Business Cycles. Federal Reserve Bank of New York Staff Reports, N 326.

Detken, C., Weeken, O., Alessi, L., Bonfim, D., Boucinha, M. M., Castro, C., Frontczak, S., Giordana, G., Giese, J., Jahn, N., Kakes, J., Klaus, B., Lang, J. H., Puzanova, N. and Welz, P. (2014). Operationalising the Countercyclical Capital Buffer: Indicator Selection, Threshold Identification and Calibration Options. ESRB Occasional Paper, N 5.

Eickmeier, S. (2005). Common Stationary and Non-Stationary Factors in the Euro Area Analysed in a Large Scale Factor Model. Deutsche Bundesbank Discussion Paper Series 1: Studies of the Economic Research Centre, N 2. 
Engle, R. and Watson, M. (1981). A One-Factor Multivariate Time Series Model of Metropolitan Wage Rates. Journal of the American Statistical Association, 76(376), pp. 774-781.

Forni, M., Hallin, M., Lippi, M. and Reichlin, L. (2000). The Generalized Dynamic Factor Model: Identification and Estimation. The Review of Economics and Statistics, 82(4), pp. 540-554.

Forni, M., Hallin, M., Lippi, M. and Reichlin, L. (2005). The Generalized Dynamic Factor Model: One-Sided Estimation and Forecasting. Journal of the American Statistical Association, 100(471), pp. 830-840.

Forni, M., Giannone, D., Lippi, M. and Reichlin, L. (2009). Opening the Black Box: Structural Factor Models with Large Cross Sections. Econometric Theory, 25(5), pp. 1319-1347.

Freixas, X., Laeven, L. and Peydró, J.-L. (2015). Systemic Risk, Crises, and Macroprudential Regulation. MIT Press.

Fukker, G. (2017). Harmonic Distances and Systemic Stability in Heterogeneous Interbank Networks. MNB Working Papers, N 1.

Geweke, J. (1977). The Dynamic Factor Analysis of Economic Time Series. In: D. J. Aigner and A. S. Goldberger, eds., Latent Variables in Socio-Economic Models.

Amsterdam: North Holland.

Geweke, J. and Zhou, G. (1996). Measuring the Pricing Error of the Arbitrage Pricing Theory. Review of Financial Studies, 9(2), pp. 557-587.

Giannone, D., Reichlin, L. and Sala, L. (2006). VARs, Common Factors and the Empirical Validation of Equilibrium Business Cycle Models. Journal of Econometrics, 132(1), pp. 257-279.

Giannone, D., Reichlin, L. and Small, D. (2008). Nowcasting: The Real-Time Informational Content of Macroeconomic Data. Journal of Monetary Economics, 55(4), pp. 665-676.

Gorton, G. B. (2009). Information, Liquidity, and the (Ongoing) Panic of 2007. The American Economic Review, 99(2), pp. 567-572.

Gotur, P. (1985). Effects of Exchange Rate Volatility on Trade: Some Further Evidence. IMF Economic Review, 32(3), pp. 475-512.

Hakkio, C. S. and Keeton, W. R. (2009). Financial Stress: What Is It, How Can It Be Measured, and Why Does It Matter? Federal Reserve Bank of Kansas City Economic Review, Second Quarter, pp. 5-50.

Hałaj, G. and Kok, C. (2013). Assessing Interbank Contagion Using Simulated Networks. Computational Management Science, 10(2-3), pp. 157-186.

Hatzius, J., Hooper, P., Mishkin, F. S., Schoenholtz, K. L. and Watson, M. W. (2010). Financial Conditions Indexes: A Fresh Look After the Financial Crisis. NBER Working Papers, N 16150.

Holló, D. (2012). A System-wide Financial Stress Indicator for the Hungarian Financial System. MNB Occasional Papers, N 105.

Holló, D., Kremer, M. and Lo Duca, M. (2012). CISS - A Composite Indicator of Systemic Stress in the Financial System. ECB Working Paper, N 1426. 
Hooper, P. and Kohlhagen, S. W. (1978). The Effect of Exchange Rate Uncertainty on the Prices and Volume of International Trade. Journal of International Economics, 8(4), pp. 483-511.

Illing, M. and Liu, Y. (2006). Measuring Financial Stress in a Developed Country: An Application to Canada. Journal of Financial Stability, 2(3), pp. 243-265.

Kadiyala, K. R. and Karlsson, S. (1997). Numerical Methods for Estimation and Inference in Bayesian VAR-Models. Applied Econometrics, 12(2), pp. 99-132.

Kindleberger, C. P. and Aliber, R. Z. (2011). Manias, Panics and Crashes: A History of Financial Crises. London: Palgrave Macmillan.

Koop, G. and Korobilis, D. (2010). Bayesian Multivariate Time Series Methods for Empirical Macroeconomics. Foundations and Trends in Econometrics, 3(4), pp. 267-358.

Koop, G. and Korobilis, D. (2014). A New Index of Financial Conditions. European Economic Review, 71, pp. 101-116.

Kósa: “Szük Esélyünk Van Arra, Hogy Elkerüljük Görögország Helyzetét” (2010). Portfolio, 3 June. Available at: https://www.portfolio.hu/gazdasag/20100603/kosaszuk-eselyunk-van-arra-hogy-elkeruljuk-gorogorszag-helyzetet-134056 [accessed on 4 February 2020].

Kose, M. A., Otrok, C. and Whiteman, C. H. (2003). International Business Cycles: World, Region and Country-Specific Factors. American Economic Review, 93(4), pp. 1216-1239. doi: 10.1257/000282803769206278

Lopes, H. F. and West, M. (2004). Bayesian Model Assessment in Factor Analysis. Statistica Sinica, 14(1), pp. 41-67.

Merton, R. C. (1974). On the Pricing of Corporate Debt: The Risk Structure of Interest Rates. The Journal of Finance, 29(2), pp. 449-470.

Nelson, W. R. and Perli, R. (2007). Selected Indicators of Financial Stability. Risk Measurement and Systemic Risk, 4, pp. 343-372.

Otrok, C. and Whiteman, C. H. (1998). Bayesian Leading Indicators: Measuring and Predicting Economic Conditions in Iowa. International Economic Review, 39(4), pp. 997-1014.

Páles, K. and Varga, L. (2008). Trends in The Liquidity of Hungarian Financial Markets What Does the MNB's New Liquidity Index Show? MNB Bulletin, 3(1), pp. 44-51. Available at: http://www.mnb.hu/letoltes/mnb-bull-2008-04-judit-pales-lorant-vargaen.pdf [accessed on 4 February 2020].

Sargent, T. J. and Sims, C. A. (1977). Business Cycle Modeling Without Pretending to Have Too Much A Priori Economic Theory. In: C. A. Sim, ed., New Methods in Business Cycle Research. Minneapolis: Federal Reserve Bank of Minneapolis, pp. 145-168.

Siddiqi, N. (2012). Credit Risk Scorecards: Developing and Implementing Intelligent Credit Scoring. John Wiley and Sons.

Sims, C. (1988). Bayesian Skepticism on Unit Root Econometrics. Journal of Economic Dynamics and Control, 12(2-3), pp. 463-474. 
Stock, J. H. and Watson, M. W. (2002). Forecasting Using Principal Components from a Large Number of Predictors. Journal of the American Statistical Association, 97(460), pp. 1167-1179.

Stock, J. H. and Watson, M. W. (2005). Implications of Dynamic Factor Models for VAR Analysis. NBER Working Paper, N 11467.

Uhlig, H. (1994). What Macroeconomists Should Know about Unit Roots: A Bayesian Perspective. Econometric Theory, 10(3-4), pp. 645-671.

Vége a Végtörlesztésnek: Több Mint 260 Milliárdot Buktak a Bankok (2012).

Portfolio, 12 March. Available at: https://www.portfolio.hu/bank/20120312/vege-a-

vegtorlesztesnek-tobb-mint-260-milliardot-buktak-a-bankok-164188

[accessed on 4 February 2020]. 